\title{
Materials Challenges in Present and Future Wind Energy
}

\author{
Brian Hayman (Det Norske Veritas AS and University of Oslo, Norway) \\ Jakob Wedel-Heinen (Det Norske Veritas, Danmark A/S, Denmark) \\ Povl Brøndsted (Risø-DTU, National Laboratory for Sustainable Energy, The Technical \\ University of Denmark, Denmark)
}

\begin{abstract}
The main concept currently in use in wind energy involves horizontal-axis wind turbines with blades of fiber composite materials. This turbine concept is expected to remain as the major provider of wind power in the foreseeable future. However, turbine sizes are increasing, and installation offshore means that wind turbines will be exposed to more demanding environmental conditions. Many challenges are posed by the use of fiber composites in increasingly large blades and increasingly hostile environments. Among these are achieving adequate stiffness to prevent excessive blade deflection, preventing buckling failure, ensuring adequate fatigue life under variable wind loading combined with gravitational loading, and minimizing the occurrence and consequences of production defects. A major challenge is to develop cost-effective ways to ensure that production defects do not cause unacceptable reductions in equipment strength and lifetime, given that inspection of large wind power structures is often problematic.
\end{abstract}

\section{Introduction}

Wind energy can be used to power individual installations directly or to generate electricity to be fed into a distribution system. Individual wind-powered installations can be either fixed, as in pumps, or moving, as in ships. Although the application of wind power to generate electricity is by far the most widespread application, it should be mentioned that studies are in progress to apply wind energy in other ways. An example is the E/S Orcelle zero-emissions cargo ship concept, ${ }^{1}$ proposed by a Scandinavian shipping company to use only renewable energy sources, including the sun, wind, and waves, as well as fuel cell technology, to meet all propulsion and onboard power requirements.

\section{Why Wind Energy?}

Wind energy is clean and renewable, in the sense that production of wind energy, once the equipment is installed, during the operational phase, does not result in any form of solid, liquid, or gaseous emissions or residues, nor does it involve the depletion of any form of fuel, whether natural or manufactured. No hazardous waste is generated, and no $\mathrm{CO}_{2}$ or toxic fumes are emitted. The only forms of negative environmental impact in the operational phase are noise and visual disturbance, as well as possible effects on flora and wild life; these aspects may be a hindrance to installation in certain locations, but there are many locations where they are not a significant issue.

The time frame from planning to installation of new wind power can be on the order of months (although currently there is a delivery time of about 2 years for wind turbines), and there are no fuel costs that can threaten the potential return on investment. Lifecycle energy balance estimates indicate that the energy required for the combined installation and end-of-life disposal phases of a wind power system is typically recovered in 6-12 months of operation. With a standard lifetime of 20 years this means an energy yield factor (the ratio of energy produced to energy consumed) of between 20 and 40 .

The main disadvantage is that wind turbines deliver power not according to the demand but according to the wind speed. Existing electrical distribution systems cannot accumulate and store the electrical energy generated and distribute it when it is needed. (See the article by Whittingham in this issue for more information on electrical storage.) Thus, wind energy will have to be combined with other sources of energy until much more widespread means of storing electrical energy become available. Also, wind power requires a distributed power transmission network that is different from the type of distribution system needed for a small number of large power stations. A further disadvantage at present is that, although the lifecycle energy yield ratio is favorable, the cost of producing electrical energy from wind at most locations is still uncompetitive, so that subsidies and incentives are needed in order to make wind energy attractive.

\section{Where Should Wind Power Be Installed?}

Clearly, wind power is feasible only where the wind climate is suitable. However, there are a great many suitable locations. Wind maps are available for Europe ${ }^{2}$ (Figure 1) and for many individual countries and states, ${ }^{3,4}$ with varying degrees of detail. Global wind maps have been compiled by Archer and Jacobson. ${ }^{5}$

\section{Wind Energy Statistics and Trends}

At present, wind energy accounts for a small fraction of total electrical energy consumption worldwide. However, the contribution is growing rapidly: In the 10 years between 1996 and 2006 , it rose from $0.1 \%$ to $0.8 \%{ }^{6}$ Whereas electrical energy consumption increased by about $3.5 \%$ annually during this period, the average annual increase in the energy generated from wind 


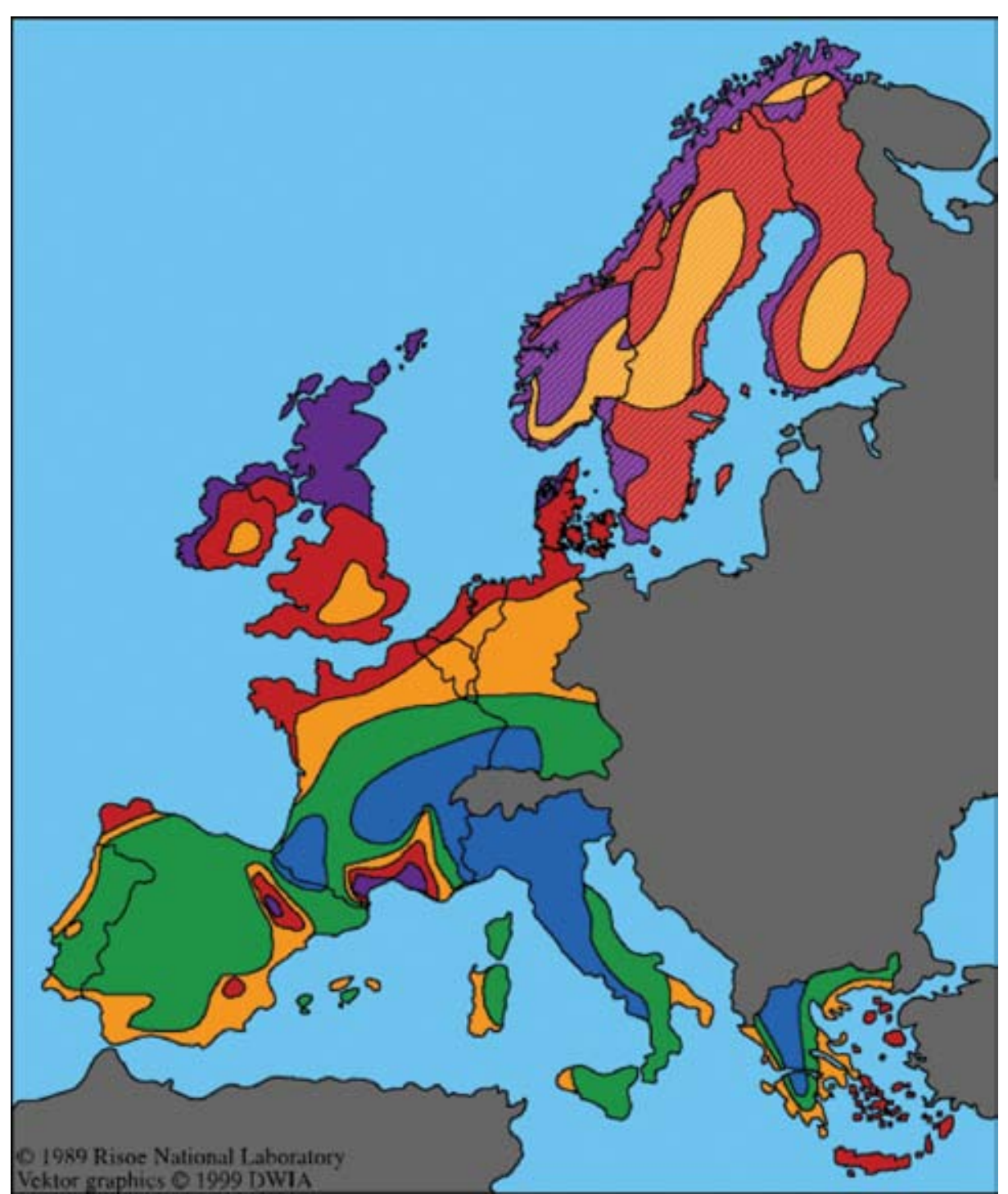

Wind Resources at 50 (45) m above Ground Level

\begin{tabular}{|c|c|c|c|c|c|c|c|c|c|c|}
\hline \multirow[t]{3}{*}{ Color } & \multicolumn{2}{|c|}{$\begin{array}{l}\text { Sheltered } \\
\text { terrain }\end{array}$} & \multicolumn{2}{|c|}{ Open plain } & \multicolumn{2}{|c|}{ At a sea coast } & \multicolumn{2}{|c|}{ Open sea } & \multicolumn{2}{|c|}{ Hills and ridges } \\
\hline & $\mathrm{m} / \mathrm{s}$ & $\mathrm{W} / \mathrm{m}^{2}$ & $\mathrm{~m} / \mathrm{s}$ & $\mathrm{W} / \mathrm{m}^{2}$ & $\mathrm{~m} / \mathrm{s}$ & $\mathrm{W} / \mathrm{m}^{2}$ & $\mathrm{~m} / \mathrm{s}$ & $\mathrm{W} / \mathrm{m}^{2}$ & $\mathrm{~m} / \mathrm{s}$ & $\mathrm{W} / \mathrm{m}^{2}$ \\
\hline & $>6.0$ & $>250$ & $>7.5$ & $>500$ & $>8.5$ & $>700$ & $>9.0$ & $>800$ & $>11.5$ & $>1800$ \\
\hline & $5.0-6.0$ & $150-250$ & $6.5-7.5$ & $300-500$ & $7.0-8.5$ & $400-700$ & $8.0-9.0$ & $600-800$ & $10.0-11.5$ & $1200-1800$ \\
\hline & $4.5-5.0$ & $100-150$ & $5.5-6.5$ & $200-300$ & $6.0-7.0$ & $250-400$ & $7.0-8.0$ & $400-600$ & $8.5-10.0$ & $700-1200$ \\
\hline & $3.5-4.5$ & $50-100$ & $4.5-5.5$ & $100-200$ & $5.0-6.0$ & $150-250$ & $5.5-7.0$ & $200-400$ & $7.0-8.5$ & $400-700$ \\
\hline & $<3.5$ & $<50$ & $<4.5$ & $<100$ & $<5.0$ & $<150$ & $<5.5$ & $<200$ & $<7.0$ & $<400$ \\
\hline & & & $>7.5$ & & & & & & & \\
\hline & & & $5.5-7.5$ & & & & & & & \\
\hline & & & $<5.5$ & & & & & & & \\
\hline
\end{tabular}

Figure 1. Wind map of western Europe (www.windpower.org/en/tour/wres/euromap.htm) (accessed January 2008). Note: The data for Norway, Sweden, and Finland are from a later study, are calculated for $45 \mathrm{~m}$ height above ground level, and assume an open plain. power, the Global Wind Energy Council $^{7}$ predicts the annual growth for 2006-2010 to be lower, at $19.1 \%$, largely because of limited equipment production capacity, but the market will still be increasing at an average rate of $8.4 \%$ on an annual basis.

Some geographical considerations may be relevant for an understanding of global developments in wind energy. Of the power installed in 2006, 51\% was in Europe, $23 \%$ in the Americas, and 21\% in South and East Asia. ${ }^{6}$ On a national basis, the United States represented the largest market, with Germany a close second, followed by India, Spain, and China. By far the largest supplier of wind turbine generators (WTGs) in 2006 was Denmark, with some $35 \%$ of the market, with Spain, the United States, and Germany each having between $15 \%$ and $16 \%$. In next place was India with about $8 \%$. The geographical mismatch between supply and demand has resulted in a globalization of the market for wind turbine generators, with established European companies setting up Asian subsidiaries and new manufacturers appearing alongside them.

The size of individual units is increasing steadily, because the cost of generated power per kilowatt-hour decreases with increasing turbine size. The average size of a WTG installed worldwide in 2006 was about 1.4 megawatts (MW), compared to $0.9 \mathrm{MW}$ in 2001 . The vast majority of WTGs supplied lie in the range of $0.75-2.5 \mathrm{MW}$, but the share of "multimegawatt class" $(>2.5 \mathrm{MW})$ WTGs is increasing and now stands at about $4 \%$. These generators can produce up to $6 \mathrm{MW}$ with rotor diameters up to $126 \mathrm{~m}$.

An area of rapidly increasing activity is offshore wind power, but the total installed capacity is still less than $1 \mathrm{GW}$. Denmark is in the forefront with $45 \%$ of this capacity. was about $29 \%$. The growth in wind energy is also reflected in the figures for total installed wind power (i.e., the capacity for generating electrical power from wind). In 2006, the total installed wind power worldwide increased by $25 \%$ from 59.4 to 74.3 gigawatts $(\mathrm{GW})$. The average rate of increase for the 5 years between 2001 and 2006 was $24.4 \%$. On the basis of cumulative installed

\section{Environmental Impact and Lifecycle Assessment}

Two distinct types of assessment are used when considering environmental aspects for wind turbine installations, whether for individual units or for entire wind farm projects. An environmental impact assessment (EIA) considers the effects of the 
installation and its operation on the environment at the specific location. It covers such aspects as pollution, including visual and noise pollution, and disturbances to flora and fauna that are inflicted on the local environment. It can also include impacts on human activity, such as trawling in the case of offshore locations. A lifecycle assessment (LCA), on the other hand, is a broad-ranging assessment of the consequences, taking account of the entire lifecycle, from extraction of raw materials to endof-life disposal. A lifecycle energy balance can be included in this or established separately.

Examples of EIAs and LCAs can be found on the Web sites of energy companies ${ }^{8,9}$ and wind turbine manufacturers. ${ }^{10,11}$ Recent studies by Vestas Wind Systems ${ }^{11,12}$ indicated that the energy used in manufacturing, installing, and disposing of a modern, $3 \mathrm{MW}$ unit should be recovered in the first 6.6 months of operation for an onshore installation or 6.8 months for an offshore installation, giving an energy yield ratio of about 35 for both cases if a 20-year life is assumed. The yield ratios for a $2 \mathrm{MW}$ unit were 27 and 31 for onshore and offshore installations, respectively. Ratios above 20 are similarly quoted in a more recent study by Crawford, ${ }^{13}$ who also confirmed that large units gave a higher energy yield ratio than smaller ones.

\section{Economics of Wind Energy}

The installation of wind power, as with most renewable energy, is dependent on economic incentives based on political decisions (see the article by Lave in this issue). A comprehensive overview is provided by the Global Wind Energy Council. ${ }^{7}$ An important factor behind the growth of the European wind market has been strong policy support at both European Union (EU) and national levels. The EU's Renewables Directive of 2001 established the aim of increasing the share of electricity produced from renewable energy sources (RES) in the EU from $15.2 \%$ in 2001 to $21 \%$ by 2010 , thus helping the EU to reach a RES target of $12 \%$ of overall energy consumption by 2010 . The EU Renewables Directive sets out differentiated national indicative targets. The actual incentives vary from country to country within the EU (as indeed they do worldwide), the most common being controlled feed-in tariffs, often combined with tax incentives. Some cost comparisons between different energy sources, valid in 2001 for the United States, are given by the American Wind Energy Association. ${ }^{14}$

\section{Wind Power Generator Concepts}

By far the most common type of wind turbine in use today has a rotor with three blades mounted in an approximately vertical plane, with a horizontal axis of rotation, facing the wind (Figure 2). The blades are made of fiber-reinforced plastics, sometimes in combination with wood. During a development period of some decades, this arrangement, generally known as the Danish concept, has been found to have many advantages over its competitors.

The main advantage of the forward-facing design over an arrangement with the blades downwind of the tower is that the tower itself does not shield the blades, so that the blades experience a more even loading and the turbine has a greater efficiency. However, an automatic yaw mechanism must be provided to ensure that the rotor always faces the wind direction, and the blades must be sufficiently stiff, and placed far enough ahead of the tower, to prevent collision with the tower under maximum wind conditions.

Three-blade designs are by far the most common, although two-blade designs are sometimes used. The optimum number of blades is determined largely by the need to minimize the loading on the shaft and bearings (and the variation in that loading during rotation of the rotor) while extracting as much energy as possible from the wind.

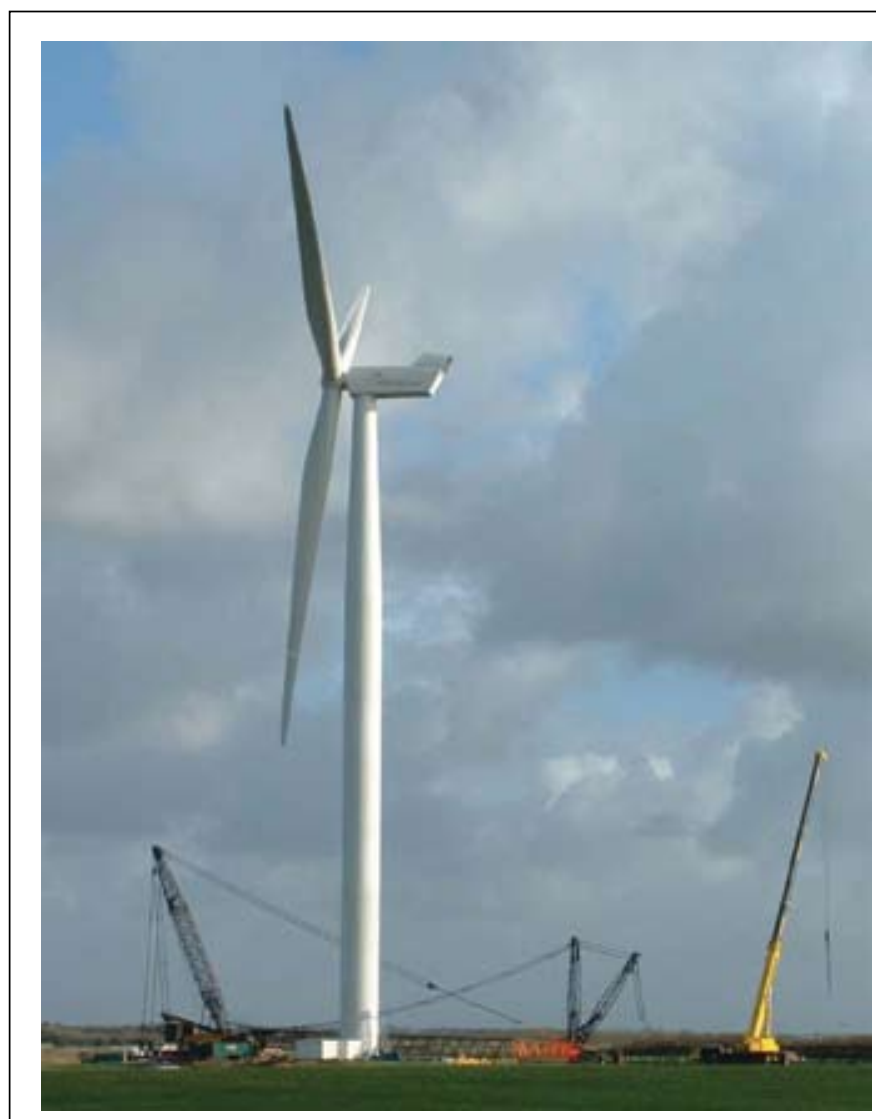

Figure 2. Modern wind turbine at Risø National Laboratory test site, Høvsøre, Denmark. The tower height is $120 \mathrm{~m}$; the rotor diameter, $110 \mathrm{~m}$; and the generator power, $3.6 \mathrm{MW}$.

Relatively few vertical-axis wind turbines have been built, and the reader is referred to a U.S. wind energy Web site for more information. ${ }^{15}$ Although, in principle, they can achieve efficiencies similar to those of horizontal-axis types, in practice, vertical-axis WTGs tend to have lower efficiencies. Furthermore, they are not inherently self-starting; the blades are susceptible to resonant vibration; and because the tower rotates with the blades, the bearings have a very large loading on them.

Because the wind speed increases and the wind flow stabilizes and becomes less turbulent with height from the ground, there are potential benefits in building wind turbines with blades as high as possible. Attempts have been made to develop novel concepts involving kites or sails, such as Kite Gen, ${ }^{16}$ but these appear to be still in the virtual modeling stage and it is unclear whether any such concepts will be applied in practice in the coming decades. There are, for example, major challenges with respect to deployment and retraction of such systems, as well as to controlling their behavior in conditions with variable wind. However, these challenges are more concerned with system design than with materials, so attention here is focused on more conventional wind turbine concepts and, in particular, on horizontal-axis turbines.

Two major developments are occurring in conventional wind power systems: First, the turbines are becoming larger, and second, there is a shift from land-based to offshore locations. Offshore sites offer very high wind exposure levels combined with relatively large areas for utilization, while often having more limited local environmental impacts. The same basic wind turbine concepts are used as for onshore installations. The main 
challenges concern foundations and supporting structures, which can be either fixed or floating and are broadly similar to those encountered in offshore oil and gas exploitation. However, the corrosive marine environment does impose additional requirements on the turbines themselves, including the blades and their attachments.

\section{Design Standards and Guidelines}

The design of modern electricity-generating wind turbines has, from the start, been subject to independent certification schemes. Initially, certification schemes were developed in Denmark, Germany, and the Netherlands in parallel with these countries' wind turbine development. In the late 1990s, the International Electrotechnical Commission (IEC) established the IEC 61400 series of standards to consolidate these different local schemes, and today, these IEC standards are taking over as reference documents for design ${ }^{17}$ and testing ${ }^{18,19}$ in the certification schemes of each country. The IEC has also proposed an overall wind turbine certification scheme. ${ }^{20} \mathrm{~A}$ design standard specifically oriented toward wind turbine supporting structures installed offshore has recently been issued by the certifying organization Det Norske Veritas (DNV)..$^{21}$

The standard IEC $61400-1{ }^{17}$ covers design of the entire wind turbine, including how to determine the design loads. The requirement for structural safety is specified in general terms and allows acknowledged steel structural design standards to be used for detailed design. For composite material blades, the extent to which IEC 61400-1 can be applied is very limited, but an interpretation of the requirements is provided in a DNV standard for the design and manufacture of wind turbine blades. $^{22}$

A comprehensive set of guidelines for the design of wind turbines is also available (DNV/Risø). ${ }^{23}$ This handbook explains in more detail much of the information presented here about wind turbine design. Guidelines for certification of both onshore and offshore wind turbines are also published by Germanischer Lloyd. ${ }^{24,25}$

\section{Blade Concepts, Materials, and Loads Blade Concepts and Loading}

Rotor blades resemble aircraft wings in that they consist of two faces, the suction side and the pressure side, which together form an optimized aerodynamic shape (Figure 3). The faces meet at the leading and trailing edges; the leading edge is rounded, but the trailing edge is sharp. The straight line between the leading and trailing edges at a given cross section is referred to as the chord line, and its length as the chord. Unlike aircraft wings, WTG rotor blades have a built-in twist, which ensures that the effective angle of attack between the blade and the air is kept roughly constant along the blade. In many turbine designs, a mechanism is also provided to rotate each blade as a whole so as to maintain the desired angle of attack under varying wind speed. Such a mechanism can also be used as a braking system. Braking of the rotor can also be achieved by mechanical or electrical means or by rotating just the tip of the blades (so-called tip brakes).

When the loadings on blades are described, the term edgewise is used to indicate loading and bending deformation in the direction of the chord line (the stiff direction), whereas flapwise indicates the direction normal to this (the more flexible direction). The main loads on the blades are the wind loads, which induce both flapwise and edgewise bending, and gravity, which induces edgewise bending when the blade is horizontal and some axial tension or compression when the blade is vertical. Torsional deformations due to the asymmetry of the blade section also need to be taken into account, as do loadings associ-

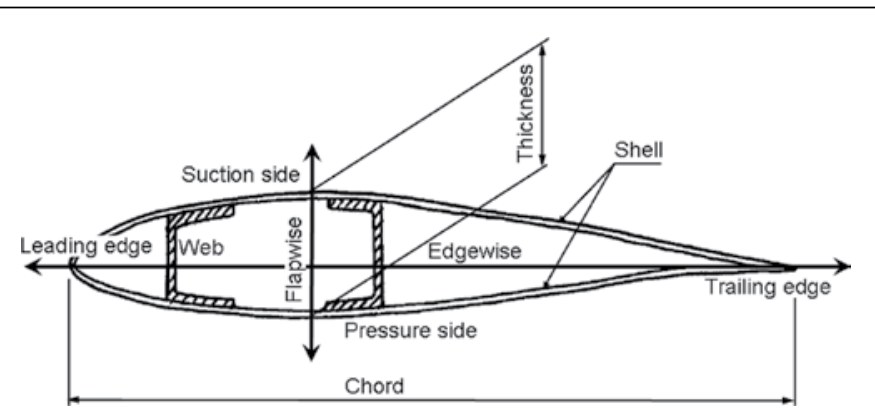

Figure 3. Schematic cross section of a blade (after Reference 26).

ated with accelerations. The loads change with time because of rotation and because of the disturbance of the air flow by the tower.

As with any other beam-like structure, bending a blade induces longitudinal tensile stresses in part of the blade section and compressive stresses in the remainder. For flapwise bending, these are predominantly the pressure and suction sides, respectively. Shear (tangential) stresses are also induced in parts of the blade. Providing effective resistance to flapwise bending is a major consideration in blade design, and the outer shell cannot usually perform this function without the assistance of some internal stiffening, as shown schematically in Figure 3. Two main arrangements are in use to provide the required bending strength and stiffness. In the first (Figure 4), the upper and lower parts of the blade shell itself are thickened to carry the longitudinal stresses caused by the bending loads. They are joined by one or more integral webs, which help to inhibit buckling of the shell and carry the shear stresses associated with flapwise bending. The second, alternative arrangement uses a box beam or spar to which the upper and lower shells are adhesively bonded (Figure 5). The flanges and webs of the box beam perform the same functions as the thickened shell parts and webs of the first arrangement. Unsupported parts of the outer shells giving the aerodynamic shape are normally built as sandwich structures.

\section{Blade Materials and Construction}

Wind turbine blades must be strong enough to withstand the applied loads without fracturing; thus, the ultimate strength must be sufficient to withstand the extreme loads, and the fatigue strength must be sufficient to withstand the time-varying loads throughout the intended life of the blade. The blades must also be stiff enough to prevent collision with the tower under extreme conditions. Stiffness, at a more local level, is

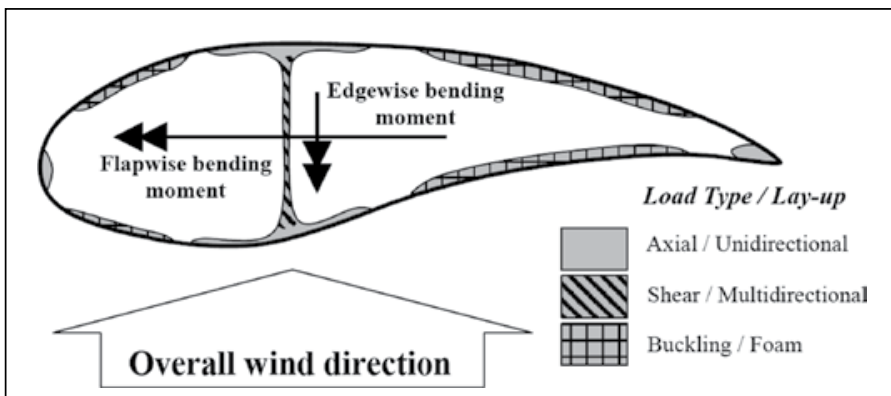

Figure 4. Cross section of blade with overall integrated beam and shell (from Reference 27). 


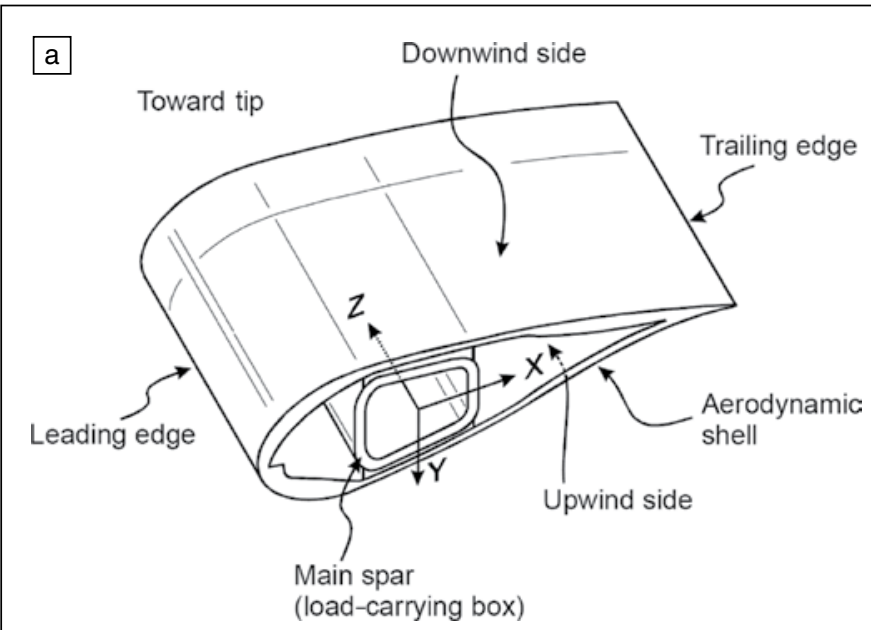

$\mathrm{b}$

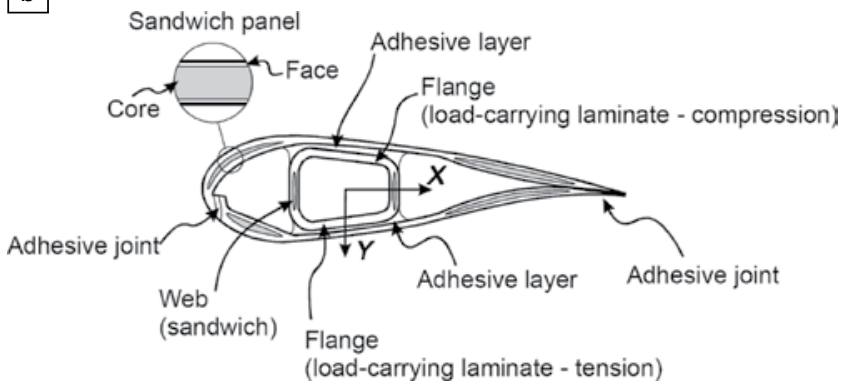

Figure 5. Section of blade with load-carrying box and attached shells: (a) perspective view, (b) cross-sectional view (from Reference 28).

also important for preventing buckling of those parts of the blade that experience compressive stresses. To minimize the cost of the power generated, the blade construction needs to be as light as possible; this has to be achieved through optimization of the structural arrangement and dimensions in parallel with the materials selection. The production processes used for manufacturing the blades must be sufficiently consistent and reliable to ensure that the end product is always compatible with the design assumptions and calculations.

To meet these demands, the blades are usually made from light, strong, and stiff material based on fiber-reinforced polymers, wood, and combinations thereof. The reinforcements are typically fabrics consisting of continuous glass fibers and/or carbon fibers. These are combined in a laminated (i.e., layered) construction with thermosetting resins, generally polyester, vinylester, or epoxy; the resulting composite materials are commonly referred to as glass-reinforced plastic (GRP) and carbonfiber-reinforced plastic (CFRP). Blades made of wood or hybrid wood/carbon fibers are normally impregnated with epoxy resin. The review by Brøndsted et al. ${ }^{29}$ and the volume edited by Lilholt et al. ${ }^{30}$ cover many of the material topics in this field.

Fiber-reinforced composites of the type used in wind turbine blades are laminates composed of several layers of reinforcing fabric impregnated with and held together by an adhesive resin. Such laminates can be very strong and stiff when loaded in their own plane, but are much weaker when loaded out-of-plane because the layers, or plies, can more readily be pulled apart. The in-plane properties are largely determined by the fibers, whereas the out-of-plane properties depend heavily on the strength and adhesive capability of the resin matrix.
Material properties depend strongly on the fiber lay-up, the fiber content, and the chosen processing route. In much of the blade cross section, the stresses are predominantly longitudinal, because of flapwise and edgewise bending loads. In these parts of the blade, unidirectional laminates dominate as performance requirements of the materials are high stiffness and strength, both in tension and in compression. In the internal webs, the main requirement is to carry shear loads. Here, we find predominantly biaxial lay-ups with the fibers at $+/-45^{\circ}$. These laminates are often built as sandwich structures to reduce the tendency for buckling. Unsupported parts of the shell giving the aerodynamic shape are also often sandwich structures with multidirectional (usually triaxial) face laminates and a light core material, such as balsa wood or a polymer foam-often poly(vinyl chloride) (PVC). The critical properties of the sandwich structure are the shear strength and stiffness of the core and compressive strength and stiffness of the faces.

The blade parts are generally assembled using adhesive bonding. The strength and durability of the adhesive bonds are major design considerations and can become the main limiting performance factor together with the performance of the laminates themselves.

\section{Qualification of Blades}

Procedures for the qualification of wind turbine blades are given by Wedel-Heinen et al. ${ }^{31,32}$ and in DNV OS-J102. ${ }^{22}$ A major part of the process involves analysis to demonstrate adequate strength and stiffness to withstand the applied loadings. The strength calculations must verify that both the ultimate strength and the fatigue strength, for a given design life (normally 20 years), are sufficient. For structural parts in compression, buckling must be considered.

\section{Design Loads}

The design loads for a wind turbine are divided into two groups: ultimate (extreme) and fatigue (cyclic) loads. IEC 61400$1^{17}$ specifies both types of loads in a way that allows for their calculation from the aeroelastic response of the wind turbine determined from time simulations of different scenarios. Modeling of the turbine's control and safety system is an important part of the aeroelastic simulation. The loads are quantified primarily in terms of the flapwise and edgewise bending moments they induce at a given cross section of the blade. Figure 6 shows a typical time simulation of these bending moments at the blade root for a multi-megawatt turbine during operation in turbulent wind flow. Transverse flapwise and edgewise shear forces, axial forces, and torsional moments also need to be established, although these loading components are often of secondary importance.

The environmental conditions are defined ${ }^{17}$ in terms of a 50 -year extreme wind speed, a frequency distribution of the wind speed, and reference turbulence. Measurements of loads on prototype turbines ${ }^{18}$ are used as a verification of the simulated extreme and fatigue loads for the turbine.

In addition to extreme wind speed, important extreme load cases are operational with high turbulence intensity in the wind flow and emergency braking of the rotor, where the blades are turned quickly to orient the chord line parallel to the rotor axis. Conditions accounting for malfunctions of the control or safety system must also be considered.

The fatigue loads for wind turbines are typically calculated from 10-min simulations of the response at 10 different wind speeds in the operational interval. Turbines are normally in operation at wind speeds of 4-25 m/s. Loads in frequent transient events such as starting and stopping are also included. 

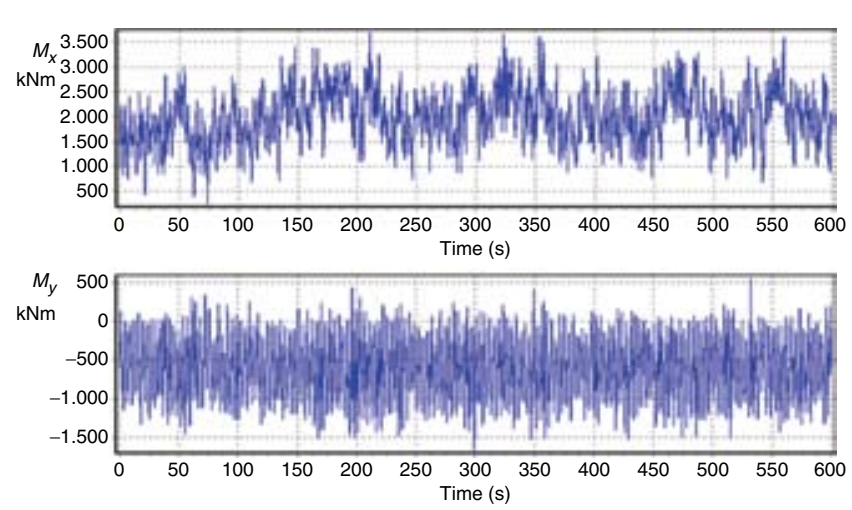

Figure 6. Flapwise and edgewise moments $M_{x}$ and $M_{y}$ at the root of a megawatt turbine in operation (from Reference 30 ).

\section{Structural Analysis}

In principle, each load case can be defined in terms of the six load components and their variations along the blade: edgewise and flapwise bending moments, edgewise and flapwise transverse shear forces, torsional moments, and axial forces (tension or compression). From these load components are calculated either stresses or strains at a series of locations in the blade. The negative influences of geometric imperfections (within the allowed manufacturing tolerances), fiber misalignments, and variable quality of workmanship need to be taken into account in the calculations. In the past, the loads on the blades were transformed into stresses or strains by use of simple elastic beam theory. For recent blade designs for megawatt turbines, the elements in the blade structure are more slender so that the blade cross section deforms during loading. In boxgirder bridge and ship hull structures, this distortion is limited by the presence of transverse internal frames or bulkheads, but such internal stiffening has not been provided in wind turbine blades thus far. Further, the strains are sensitive to buckling deformations combined with geometric imperfections. For this reason, linear or nonlinear finite element analysis is now often used to calculate the stresses or strains.

Special calculations may be necessary for the blade root, the root-blade transition, the tip brake system, bonded joints, and regions susceptible to local buckling. In some cases, it is necessary to verify the strength and rigidity of complicated substructures by means of separate full-scale tests.

To an increasing extent, the properties of laminates and structural assemblies can be predicted from numerical models, combined with knowledge of the properties of the individual fiber, matrix, and sandwich core materials and the use of cohesive laws for interfaces and joints. ${ }^{33,34}$ However, the properties must be verified by mechanical testing.

\section{Mechanical Testing}

Mechanical tests are carried out on coupons and subcomponents with a representative lay-up and a processing route similar to that of the blade in question. This includes adhesive bonds, which must be tested for sufficient static and fatigue strength. ${ }^{28,35}$ The final qualification requires full-scale tests on prototype blades. ${ }^{19,36}$

Tests for stiffness and static (ultimate) strength of materials are carried out under quasistatic loading. Fatigue tests are carried out under cyclic loading, normally with constant amplitude. Properties are measured under tensile, compressive and shear loads, or combinations thereof. The measurement of laminate properties for blade design has been the subject of a great deal of study, as there are many available test methods and ways of processing and presenting the results. Standards originally developed for the aerospace industry, which uses thin, optimized laminates with high homogeneity and only minor imperfections, have required adaptation to permit application to wind turbine blades. These aspects have been addressed in several research projects, including a series of joint European programs. Static and fatigue properties of glass-polyester and glass-epoxy laminate materials have been measured, test techniques developed, and reference design curves established. The results have been collected and summarized in a series of books ${ }^{37,38}$ and articles, ${ }^{31,32,39}$ as well as databases such as FACT ${ }^{40}$ and the more recent OptiDAT. ${ }^{41}$ In parallel with the European activity, a nationally supported program in the United States has investigated the properties of polymer composite materials for wind turbines. The results are collected in the large DOE/ MSU (Department of Energy/Montana State University) database. ${ }^{42,43}$

In the current European project UpWind, ${ }^{44}$ models for damage mechanics and micromechanics have been reviewed. ${ }^{45}$ Topics such as frequency and temperature effects, ${ }^{46}$ life extension, condition assessment, and repair will be further developed, and test methods will be systematized to form the basis for an extended standardization giving more accurate and reliable testing techniques.

\section{Design Against Fatigue}

Design of composite blades against fatigue presents special challenges. The load histories obtained as described earlier from simulation are transformed into stress (or possibly strain) histories at a given location, and a rain-flow counting procedure $^{23}$ is applied to divide the continuous histories for the individual stress components into discrete stress cycles. Each stress cycle is represented by a mean stress value and a stress range. The cycles are then grouped into a number of mean stress and stress range intervals. Based on a specified wind speed distribution over the turbine's 20 -year life, the number of cycles in each group from the 10-min simulations is scaled according to the number of hours expected at each wind speed interval. Thus, the stress cycles are summarized for the complete 20-year life of the turbine.

Individual fatigue tests of blade materials are usually carried out at constant stress amplitude. Specimens are tested at several different stress amplitudes (or ranges) and with selected values of the ratio between the minimum and maximum stresses. An interpolation procedure is used for intermediate values of the stress ratio, and the Palmgren-Miner rule is used for summing the damage from cycles of differing stress range and ratio, as is common for metals. Detailed testing with variable-amplitude loading ${ }^{31,39}$ has shown that this approach introduces a considerable amount of modeling uncertainty and that it is important to test coupons at stress ratios and ranges that are critical for the calculated fatigue life of the blade structure. Improved models for damage accumulation are needed to reduce the modeling uncertainty, allow the use of reduced partial safety factors, and provide an improved basis for optimization of design.

In addition to these issues, the procedure for fatigue life estimation assumes that coupon strength is representative of the strength of the laminates in the full-scale composite structure. However, experience with blade failures in full-scale approval tests and in the field indicates that manufacturing defects and imperfections that are not normally present in small-scale coupons can also be very important for strength. 


\section{Production Processes, Defects, and Damage Processes for Blade Production}

Currently, the most commonly used processes for production of the blade components involve resin infusion, generally vacuum-assisted. However, in some designs, fabrics that have been preimpregnated with resin (called prepregs) are laid up, covered by a sealed vacuum bag, and then cured by heating under vacuum. These processes have replaced the hand-layup processes used previously, largely to avoid exposure of the workforce to harmful fumes. The completed shell components making up the aerodynamic surfaces are joined to each other and to the internal parts using adhesive bonding.

\section{Production Defects}

Many types of production defects can arise in the composite production and bonding processes. Overviews are provided by Åström ${ }^{47}$ and Hayman et al. ${ }^{48}$

For single-skin (solid) laminates and face laminates of sandwich structures, production defects include

- delaminations;

- dry zones and voids;

- poor curing (giving reduced physical properties);

- wrinkles;

- fiber reinforcement defects; and

- misalignment of fibers, both small-scale (fiber waviness) and larger.

For sandwich structures, core/skin debonds must also be considered, as well as voids and inclusions in the core and lack of bonding at joints between blocks of core material.

Geometric imperfections can occur at a number of different levels, ranging from local out-of-straightness of the fiber tows associated with the weaving or stitching process to global outof-straightness or out-of-flatness in beams or panels. Geometric imperfections also include eccentricities of loading introduced at joints between structural elements and steps associated with joints and overlaps.

Defects in bonded joints are mainly of two types: voids due to partial filling of the joint with adhesive, often caused by badly fitting parts, and lack of adhesion caused by contamination or poor preparation of the surfaces to be joined.

At present, the defects and imperfections that appear to be of most concern in wind turbine blade production are delaminations, bond defects, wrinkles, and other geometric imperfections that give rise to local stress concentrations (and thus to reduction of strength and shortening of fatigue life). Larger geometric imperfections that influence the buckling resistance are also of concern.

\section{Consequences of Production Defects}

As production defects in composites can be of many types and sizes, their influence on structural behavior can vary greatly. Generally, production defects reduce the strength and lifetime of the structure as compared to the corresponding properties of a defect-free structure. They can also reduce the stiffness, but generally the effect on stiffness is less than that on strength, as changing the stiffness of a part requires a change in the properties of a significant volume of material whereas the strength can be reduced by very localized changes.

Some types of production defects are small and are distributed through the material so that they are taken into account in the material testing, provided that the test specimens are taken from a batch of material that is typical for the production of the blades themselves. However, many types of defects and imperfections require specific consideration.

In structural design, defects and imperfections are normally taken into account at the design stage by using appropriate safety margins or knock-down factors when assessing the structure's strength in relation to the loads it is intended to resist. If the extent of defects and thus their effects on strength are not well understood, it is necessary to build in large safety margins to cover this uncertainty. For composite structures, such an approach can lead to unnecessarily conservative designs that are not economically (or even technically) viable, but if these margins are not built into the design, there can be an unacceptable risk that the structure will fail as a result of the presence of defects.

The industry needs to have a good understanding of the causes of production defects and imperfections and the measures that can be taken during production to reduce or eliminate them. This is especially important when production facilities are being established at new sites, with new personnel who may lack experience in high-quality composite production. It is also important when the scale of production is increased, in terms of either size or quantity of items produced. Knowledge of the influence that a defect or imperfection of given type, size, and location can have on the strength or lifetime of a structure or component is needed in order to determine the production tolerances and the acceptance limits for defects that must be specified in a production control system.

When considering defects in metal structures, it is most common to focus on tensile stress situations, as these tend to initiate and open cracks at the defect sites. For laminated composites, defects can reduce the tensile and shear strength of the bonds between layers. They can also reduce or destroy the support the resin matrix gives to the fibers, thereby allowing them to buckle under compressive loading in the fiber direction.

An important tool in the understanding and modeling of many types of defects, especially crack-like defects such as delaminations and debonds, is the science of fracture mechanics. This science is appreciably more complex for composite materials than for metals because composites are both inhomogeneous and anisotropic.

\section{Delaminations}

Delamination is the separation of laminate plies as a result of absence or failure of the bonding between layers of reinforcement, either locally or covering a wider area. It can occur during either the manufacturing process or the subsequent service life of the laminated part. During the manufacturing process, delaminations are caused mainly by contaminated reinforcing fibers, by insufficient wetting of fibers, or by shrinkage that occurs during the curing of the resin and the resulting exotherm.

Generally, delaminations reduce the compressive strength by lowering the resistance to out-of-plane buckling of the groups of plies to either side of the delamination. Furthermore, they can grow under repeated loading, with failure occurring when the delamination reaches a critical size.

As an illustration, a series of tests by Short et al. ${ }^{49}$ on flat and curved GRP specimens showed that compressive failure loads were, in some cases, reduced by as much as $34 \%$ by the presence of a delamination, whereas a study by Hwang et al. ${ }^{50}$ showed that multiple delaminations, which tend to occur when a laminate suffers impact damage, led to as much as a $65 \%$ reduction.

\section{Sandwich Debonds}

Among the most critical types of defects in sandwich structures is an absence of connection between the face and the core, generally referred to as a debond or disbond. This kind of defect resembles delamination in a solid laminate but can be highly critical to the sandwich structure, as the basic sandwich principle is compromised. 
Debonds can occur in production if the adhesive layer forming the interface between the face and the core is absent in parts of the panel or if the adhesion is deficient as a result of inadequate surface preparation or incomplete curing. Debonds occurring as production defects may be difficult to identify, as they do not necessarily cause any visible disturbance to the face sheet, although they can often be detected by tapping a coin or light hammer on the surface. Debonds can also occur as a result of in-service damage.

The influence of debonds on the strength of foam-cored sandwich panels was investigated both experimentally and theoretically using an advanced mixed-mode fracture mechanics approach by Berggreen and co-workers. ${ }^{51-53}$ Thus far, the studies have been mainly confined to cases with single loading, but damage growth under repeated loadings is currently being studied.

\section{Wrinkles}

Wrinkles can arise in single-skin (solid) laminates and in face laminates of sandwich composites. A wrinkle is caused by an excess of reinforcement in one or more of the plies in relation to the surface area available when the reinforcement is being placed. These plies are unable to lie completely flat and therefore form a small, outward buckle or wrinkle. The wrinkle can involve only the outermost plies of the laminate, but it can also start deeper down in the lay-up, even involving the entire thickness in extreme cases (Figure 7). Wrinkles can significantly reduce the compressive strength of a laminate for in-plane loading applied perpendicularly to the line of the wrinkle. In singleskin laminates, the strength reduction is often so severe that the defect has to be repaired or the component rejected. However, in sandwich configurations, the core seems to have a stabilizing effect so that the strength reduction is less dramatic. ${ }^{54}$ In wind turbine blades, a major concern is the reduction in fatigue life that can result from the stress concentration at a wrinkle.

\section{Geometric Imperfections}

Geometric imperfections in composite structures have been discussed by Hayman et al. ${ }^{48}$ and Berggreen et al. ${ }^{55}$ Such imperfections consist essentially of two main types: out-of-straightness or out-offlatness within components and eccentricities or misalignments at connections. They can exist at many different scales in a composite component or structure and have many different causes. Geometric imperfections can never be totally eliminated, but to some extent, it is possible to limit their size by careful design of the production processes and then to take them into account in design.

At the most local level, waviness in the reinforcing fibers can significantly reduce the compressive strength of unidirectional laminates, especially those with carbon reinforcements. Fiber waviness can be either in-plane or out-of-plane. For a unidirectional material, several models have been developed to determine theoretically the compressive failure due to microbuckling. Budiansky ${ }^{56}$ presented a model in which this "kinking" phenomenon was described for an elastic-perfectly plastic, unidirectional composite. Soutis, Curtis, andFleck ${ }^{57}$ investigated the applicability

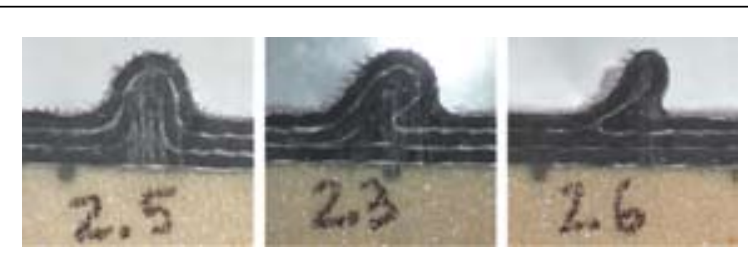

Figure 7. Sections through wrinkle defects of differing depths in a sandwich face laminate. The face laminate thickness is $\sim 5.4 \mathrm{~mm}$ in each of the cases shown. of this model to multiaxial CFRP lay-ups. These studies showed that an increase in the imperfection angle by just a few degrees reduces the compressive strength dramatically. The effect of this type of defect is taken into account in the material testing provided the test samples are representative for the blade production process.

Most types of geometric imperfections cause increases of local stresses that can reduce the fatigue life of a blade. Larger scale geometric imperfections arising in the curing process influence the performance of components and structures that are subject to buckling failure.

\section{Failure Involving Buckling}

Taking adequate account of buckling effects in combination with production defects and geometric imperfections presents considerable challenges in the design of wind turbine blades, especially as blades become larger and more highly optimized. In contrast to design of metal structures, design of FRP structures against buckling normally follows a much simplified approach based on the calculation of an elastic critical load of the idealized, geometrically perfect structure, at best modified by a knock-down factor to account for the effects of geometric imperfections and residual stresses. A separate check for local material failure is performed, but usually, this does not consider the amplification of stresses that results from buckling deformations in combination with imperfections. This is probably due to the facts that relatively few test results are available for buckling of FRP structures and that there is little published information on the manufacturing imperfections for which allowance needs to be made. An additional aspect is that composite structures generally have a lower sensitivity to geometric imperfections than many of their much thinner metal counterparts. However, this does not mean that the effects of geometric imperfections can be neglected. Furthermore, for thicker composites, the effects of the shear deformation that occurs through the laminate section need to be taken into account in the buckling assessment, as illustrated recently for thick cylindrical composite shells by Vedeld. ${ }^{58}$

\section{Defect and Damage Tolerance}

As described previously, the issues of understanding production defects, limiting their occurrence, and taking into account in blade design those defects and imperfections that may arise are critical aspects of wind turbine production. Different production defects and imperfections influence the structural performance in different ways, and it is important to have models that reflect these different influences. A number of theoretical and empirical models exist or are under development to predict the reductions of strength that result from such defects and imperfections, as well as from transportation damage and in-service damage such as that caused by bird, hail, and ballistic impacts. Combining these models of local phenomena with the global strength modeling of a large structure such as a wind turbine blade presents some challenges, and there is a need to develop rational but manageable procedures for doing so. Approaches such as that proposed by Hayman ${ }^{59}$ for defect and damage assessment of ship hulls built from sandwich composites may find some application in this context.

Even greater challenges arise with respect to the types of defects and damage that can grow as the structure is subjected to repeated loadings in service. The effects of small defects that are inherent in, and typical for, a given production process can be taken into account in the fatigue properties obtained from tests on representative coupon specimens; the uncertainties that nonetheless exist in fatigue design have already been mentioned. Larger defect types such as delaminations and debonds require 
more specific attention. In some cases, damage growth can cause the structure to fail, or at least decrease the residual strength such that the margin of safety is reduced to an unacceptably low level. In other cases, the redistribution of stresses or the introduction of new mechanisms such as fiber bridging giving increased crack resistance can cause the damage growth to slow and eventually stop. These growth phenomena in composites are still not fully understood, and damage growth models for composites are less well established than are those for metals.

When models for damage growth are available, it is possible to use damage tolerance principles in design and in inspection and maintenance planning. The basic principle is that one determines the growth rate and maximum damage size that are acceptable for the structure to perform satisfactorily. Then, one ensures that inspection is carried out both immediately after production and at specified intervals during the service life of the structure such that an undetected defect or damage cannot grow to an unacceptable level in the interval before the next inspection. This approach is required, for example, by the U.S. Federal Aviation Authority Rules ${ }^{60}$ in the case of composite structures used in aircraft. However, failure in an aircraft structure can involve the loss of many lives as well as high economic losses, and the qualification, production, and maintenance regimes reflect this. It is yet to be seen whether this kind of approach can be usefully and economically applied to wind turbine blades. ${ }^{59}$

\section{The Challenges \\ Existing Materials}

As already discussed, the main challenges related to the application of existing materials concern fatigue life prediction methods and the development of models to describe the effects of production defects and imperfections on the strength and lifetime of a wind turbine blade.

\section{New Materials}

In the longer term, there is scope for improving the materials used in wind turbine blades. As indicated previously, wind turbine blades need to be strong, stiff, and of low weight. Two particular weaknesses of laminated fiber-reinforced composites are their low tensile and shear strength in the out-of-plane direction and the fact that developments that increase their stiffness and tensile strength in the fiber direction do not generally have the same beneficial effect on the compressive strength. A further consideration is recyclability: The thermosetting resins currently used cannot be recycled, and the only disposal method for fiber-reinforced composites containing these resins is to break the composite up into small pieces and incinerate them, feeding the heat into a district heating system, for example. This is not necessarily a major disadvantage, but greater flexibility with regard to recycling and disposal is desirable.

Carbon fiber reinforcements are being introduced into blades. These can be used to improve the stiffness and tensile strength in the fiber direction, as compared to materials containing glass, but the gains in compressive strength are generally significantly lower. Thus, it is often most economical to use a mixture of glass and carbon, with carbon being used mainly to increase the global blade stiffness. The same is likely to apply to any new high-strength and high-stiffness reinforcement fibers that may be introduced.

At present, moderately priced polymer resins and adhesives tend to be either strong, stiff, and brittle or weak, compliant, and tough. The development of products that provide a better combination of strength (including good adhesion), stiffness, and toughness than those available at present would be a great step forward. However, such materials must not degrade in service and should, if possible, be recyclable. As mentioned by Brøndsted et al., ${ }^{29}$ thermoplastic resins offer a number of advantages, including high toughness and a higher degree of recyclability. Disadvantages are the high temperatures needed during blade production and the difficulty in bonding finished parts together.

Environmental considerations may also lead to greater interest in renewable materials such as natural cellulose fibers for reinforcement and biobased resins, rather than polymer materials based on oil.

\section{Improved Structural Design}

In addition to the introduction of new materials, the structural design of blades offers some potential for development. The three data points to the extreme right in Figure 8 show the weight reductions that have already been achieved in recent years for fiber composite blades, through improved structural arrangements combined with some use of carbon fiber reinforcements. The structural design of the heavy root section of rotor blades has been optimized, leading to thinner root diameters and thus smaller, lighter, and less expensive hubs. As mentioned previously, further optimization of blades and increases in their size mean a greater susceptibility to buckling failures and a need for better methods for taking account of the effects of geometric imperfections. There is also a need to develop practical approaches for achieving damage tolerant design.

The special behavior of anisotropic nonsymmetrical laminates under combined bending and twisting has been exploited to design composite laminates and blade structures in which the blade bends and twists simultaneously, in a predetermined way. Thus, the aerodynamic profile of the rotor blade can be made to adjust itself optimally at low wind speeds for maximum aerodynamic performance and to twist itself out of the wind at high wind speeds so that the loads on the blade are reduced. This replaces the need for a conventional pitch control mechanism, which is generally slow to respond to gusts. There is a potential for further development of such "smart" blades.

\section{Nondestructive Inspection and Structural Health Monitoring}

The ability to deal effectively with production defects will be central to the cost-effective production of larger blades. An important aspect is the ability to detect unacceptable defects at an early stage. This is a formidable task for nondestructive inspection (NDI) because of the large areas and curved shapes that have to be scanned, the difficulty of accessing internal parts, and the variety of defect types that may be present. Although much progress has been made in the development of NDI techniques for composites in recent years, ${ }^{59,61}$ this area still presents some major challenges. Currently most blades are subjected only to visual inspection. In some cases, inspection is

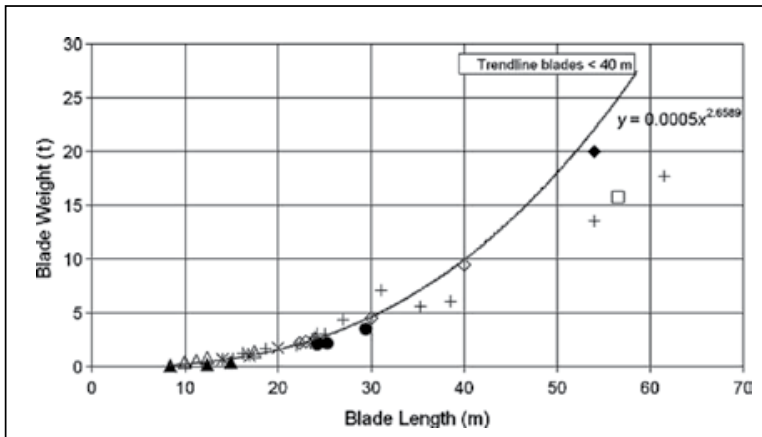

Figure 8. Development in rotor blade weight versus length. Symbols indicate different manufacturers and processing technologies (from Reference 29). 
performed using the pulse-echo ultrasound technique, which can be readily built into a rapid scanning system. However, it cannot detect all kinds of defects in all materials. Thick sandwich materials present special challenges for NDI, and at present, it is necessary to use a combination of different NDI techniques, some requiring access from both sides of the sandwich, if all important defect types are to be detected.

In view of the uncertainties still present in the prediction of degradation due to fatigue, especially in the presence of undetected production defects, it is also of great interest to be able to monitor degradation of a blade while in service and to detect the incidence of damage due to events such as lightning strikes and hailstorms. Structural health monitoring systems, based on acoustic emission, optical fibers, and advanced sensor technology, are under development to allow continuous recording of important parameters for the state of degradation of the materials and to predict remaining lifetime with the aid of damage models. An unexpected change in the state of degradation, if detected, can be used to initiate inspection, repair, or replacement of rotor blades.

\section{Conclusions}

The installation of wind power is growing rapidly and is expected to continue to do so for many years to come. At present, the majority of the production of wind turbines is located in Europe, while the major markets now include Asia and the Americas. Much of the necessary expansion of production capacity for wind turbines can be expected to occur in Asia.

In the foreseeable future, it is expected that the horizontalaxis wind turbine concept, most commonly with three blades made of composite materials, will continue to dominate in the generation of electrical power from wind. This applies to both land-based and offshore applications. As the units become larger and more highly optimized, stiffness, strength, and fatigue life will continue to be the main design considerations for the blades, with the prevention of buckling failure having increasing importance. The main materials challenges will be to ensure a consistent quality in production as the blades become larger, as new large-scale production facilities are established and as variations in production techniques are introduced, and to take into account in a cost-effective way those production defects and geometric imperfections that may be present. Improved knowledge of defects, their causes, and their influence on structural behavior under both static and time-varying loads will be essential to achieve this.

\section{References}

1. Wallenius Wilhelmsen Logistics, "E/S Orcelle-Environmentally Sound Ship," (Wallenius Wilhelmsen Logistics; www.walleniusmarine.com/qse. jsp?art_id=120) (accessed January 2008).

2. Danish Wind Industry Association, "Wind map of Western Europe," (Danish Wind Industry Association; www.windpower.org/en/tour/wres/euro map.htm) (accessed January 2008).

3. U.S. Department of Energy, Energy Efficiency and Renewable Energy, "Wind Resource Maps," (USDOE, EERE; www.eere.energy.gov/windandhy dro/windpoweringamerica/wind_maps.asp) (accessed January 2008)

4. U.S. Department of Energy, Renewable Resource Data Center, "Wind Energy Resource Atlas of the United States," (USDOE, RRDC; http://rredc. nrel.gov/wind/pubs/atlas/maps.html) (accessed January 2008).

5. C.L. Archer, M.Z. Jacobson, J. Geophys. Res. 110, D12110 (2005).

6. International Wind Energy Development-World Market Update 2006 (BTM Consult ApS, March 2007).

7. Global Wind Energy Council, "Global Wind 2006 Report," (GWEC, 2006; www.gwec.net/fileadmin/documents/Publications/gwec-2006_final_01.pdf) (accessed January 2008).

8. DONG Energy Web site; www.hornsrev.dk/Engelsk/default_ie.htm (accessed January 2008).
9. ELSAMPROJEKT A/S, "Horns Rev. Offshore Wind Farm-Environmental Impact Assessment-Summary of EIA Report" (ELSAMPROJEKT A/S, Fredericia, Denmark, May 2000; www.hornsrev.dk/Engelsk/Miljoeforhold/ pdf/Resume_eng.pdf) (accessed January 2008).

10. Vestas Wind Systems Web site; http://www.vestas.com/en/about-vestas/ sustainability/wind-turbines-and-the-environment (accessed January 2008). 11. Vestas Wind Systems, "Life Cycle Assessment of Offshore and Onshore Sited Wind Power Plants Based on Vestas V90-3.0 MW Turbines" (Vestas Wind Systems, Randers. Denmark, Ed. 2, July 2006; http://www.vestas.com/ Admin/Public/Download.aspx?File=/Files/Flier/EN/Sustainability/LCA/ LCAV90_juni_2006.pdf (accessed January 2008).

12. Vestas Wind Systems, Environmental Impact of Wind Turbines: Energy Balances, http://www.vestas.com/Admin/Public/Download.aspx?File=/Files/ Filer/ EN/Sustainability/LCA/LCA_V80_2004_UK.pdf (accessed January 2008). 13. R.A. Crawford, "Life-Cycle Energy Analysis of Wind Turbines-An Assessment of the Effect of Size on Energy Yield," in Energy and Sustainability, C.A. Brebbia and V. Popov, Eds., Transactions of the Wessex Institute, Ecology and the Environment (WIT Press, Wessex, UK, 2007); Vol. 105, p. 155.

14. American Wind Energy Association, Comparative Cost of Wind and Other Energy Sources (American Wind Energy Association, Washington, DC, 2001; www.awea.org); (accessed January 2008).

15. E. Eggleston, AWEA staff, "What are Vertical-Axis Wind Turbines (VAWTs)?" (American Wind Energy Association, Washington, DC; www. awea.org/faq/vawt.html) (accessed January 2008).

16. Kite Gen Web site; www.kitegen.com (accessed January 2008).

17. International Electrotechnical Commission, IEC 61400-1, Wind TurbinesPart 1, Design Requirements, ed. 3 (IEC, Geneva, Switzerland, 2005)

18. International Electrotechnical Commission, IEC 61400-13, Wind Turbine Generator Systems-Part: 13, Measurement of Mechanical Loads (IEC, Geneva, Switzerland, 2001).

19. International Electrotechnical Commission, IEC 61400-23, Technical Specification, Wind Turbine Generator Systems-Part: 23, Full-Scale Structural Testing of Rotor Blades (IEC, Geneva, Switzerland, 2001).

20. International Electrotechnical Commission, IEC WT 01, IEC system for Conformity Testing and Certification of Wind Turbines, Rules and Procedures (IEC, Geneva, Switzerland, 2001).

21. Det Norske Veritas, Offshore Standard DNV-OS-J101 Design of Offshore Wind Turbine Structures (Det Norske Veritas, Høvik, Norway, 2004).

22. Det Norske Veritas, Offshore Standard DNV-OS-J102 Design and Manufacture of Wind Turbine Blades, Offshore and Onshore Wind Turbines (Det Norske Veritas, Høvik, Norway, 2006).

23. Det Norske Veritas, Risø National Laboratory, Guidelines for Design of Wind Turbines (Det Norske Veritas and Risø National Laboratory, Copenhagen, Denmark, 2002)

24. Guideline for the Certification of Wind Turbines (Germanischer Lloyd, Hamburg, Germany, 2003, with Supplement, 2004).

25. Guideline for the Certification of Offshore Wind Turbines (Germanischer Lloyd, Hamburg, Germany, 2005).

26. C. Skamris, Ed., B. Vestergaard, J. Wedel-Heinen, K.M. Halling, 0. Sønderby, J.J. Kristensen, B. Pedersen, P. Brøndsted, C.L. Thomsen, E. Bjerregaard, Type Approval Scheme for Wind Turbines. Recommendation for Design Documentation and Test of Wind Tturbine Blades (Danish Energy Agency, Copenhagen, Denmark, 2002).

27. R. Nijssen, doctoral thesis (KC-WMC and Faculty of Aerospace Engineering, Delft University, Delft, The Netherlands, 2006).

28. B.F. Sørensen, E. Jørgensen, C.P. Debel, F.M. Jensen, H.M. Jensen, T.K. Jacobsen, K. Halling, "Improved Design of Large Wind Turbine Blade of Fiber Composites Based on Studies of Scale Effects (Phase 1)—Summary Report," (Report Risø-R-1390(EN), Risø National Laboratory, Roskilde, Denmark, 2004)

29. P. Brøndsted, H. Lilholt, A.A. Lystrup, Ann. Rev. Mater. Res. 35, 505 (2005).

30. H. Lilholt, B. Madsen, T.L. Andersen, L.P. Mikkelsen, A. Thygesen, Eds., Proc. 27th Risø Conference on Materials Science, Polymer composite materials for wind power turbines (Risø National Laboratory, Roskilde, Denmark, 4-7 September 2006).

31. J. Wedel-Heinen, J.K. Tadich, C. Brokopf, L.G.J. Janssen, A.M. van Wingerde, D.R.V. van Delft, C.W. Kensche, T.P. Philippidis, P. Brøndsted, A. G.Dutton, R.P.L. Nijssen, Implementation of OPTIMAT in Technical Standards, OB_TG6_R002 rev. 8, ENK6-CT-2001-00552 PROJECT N ${ }^{\circ}$ : NNE5-2001-00174, OPTIMAT BLADES (2006).

32. J. Wedel-Heinen, J.K. Tadich, Proc. 27th Risø Conference on Materials Science, Polymer Composite Materials for Wind Power Turbines, 115 (Risø National Laboratory, Roskilde, Denmark, 2006).

33. B.F. Sørensen, P. Kirkegaard, Eng. Fract. Mech. 73, 2642 (2006).

34. C. Lundsgaard-Larsen, B.F. Sørensen, C. Berggreen, R.C. Østergaard, Proc. 27th Risø Conference on Materials Science, Polymer Composite 
Materials for Wind Power Turbines, (Risø National Laboratory, Roskilde, Denmark, 2006) p.375.

35. B.F. Sørensen, K. Branner, H. Stang, H.M. Jensen, E. Lund, T.K. Jacobsen, K.M. Halling, "Improved Design of Large Wind Turbine Blades of Fiber Composites (Phase 2)-Summary Report" (Report Ris $\varnothing-R-1526(E N)$, Risø National Laboratory, Roskilde, Denmark, 2005).

36. E.R. Jørgensen, K.K. Borum, M. McGugan, C.L. Thomsen, F.M. Jensen, C P. Debel, B.F. Sørensen, "Full Scale Testing of Wind Turbine Blade to Failure-Flapwise Loading" (Report Risø-R-1392(EN), Risø National Laboratory, Roskilde, Denmark, 2004).

37. C.W. Kensche, Ed., "Fatigue of Materials and Components for Wind Turbine Rotor Blades" (Report EUR 16684, European Commission, Luxembourg, 1996). 38. R.M. Mayer, Ed., Design of Composite Structures against Fatigue (Mechanical Engineering Publications Ltd., Suffolk, UK, 1996).

39. L.G.J. Janssen, A.M. van Wingerde, C.W. Kensche, T.P. Philippidis, P. Brøndsted, A.G. Dutton, R.P.L. Nijssen, O. Krause, "Reliable Optimal Use of Materials for Wind Turbine Rotor Blades. Final Report (OPTIMAT BLADES)" (Report ECN-C-06-023, Office for Official Publications of the European Communities, Luxembourg, 2006).

40. B.J. de Smet, P.W. Bach, Database FACT: Fatigue of Composites for Wind Turbines. 3rd IEA Symp. Wind Turbine Fatigue (ECN, Petten, The Netherlands, 1994).

41. Delft University of Technology, The Energy Research Centre of the Netherlands, "Optidat Database," (TUD, ECN; www.kc-wmc.nl/optimat blades_optidat.php) (accessed January 2008).

42. J.F. Mandell, D.D. Samborsky, "DOE/MSU Composite Materials Fatigue Database. Test Methods, Materials, and Analysis" (Report SAND97-3002, UC-1210, Sandia National Laboratory, Albuquerque, NM, 1997).

43. DOE, MSU, "DOE/MSU Composite Material Fatigue Database March 2007 Update," (DOE, MSU; www.coe.montana.edu/composites/documents/March \%202007\%20DOE_MSU\%20Database16.pdf) (accessed January 2008).

44. European Union, UpWind Project Web site; www.upwind.eu (accessed January 2008).

45. L. Mishnaevsky, Jr., P. Brøndsted, Proc. 27th Risø Conference on Materials Science, Polymer Composite Materials for Wind Power Turbines, 239 (Risø National Laboratory, Roskilde, Denmark, 2007).

46. L. Mishnaevsky, Jr., P. Brøndsted, Cyclic Loading Frequency Effect on the Damage Growth in the Low-Frequency Range. In Proceedings 239 (2006).

47. B.T. Åström, Manufacturing of Polymer Composites (Chapman and Hall, London, 1997).

48. B. Hayman, C. Berggreen, N. Tsouvalis, in Proceedings of MARSTRUCT 2007. The 1st International Conference on Marine Structures, Glasgow, United Kingdom, 12-14 March 2007 (Taylor \& Francis 2007). pp. 435-449. 49. G.J. Short, F.J. Guild, M.J Pavier, Compos. Struct. 58 (2), 249 (2002).

50. S.F. Hwang, S.M. Huang, Compos. Struct. 68, 157 (2005).

51. C. Berggreen, PhD degree thesis, Department of Mechanical Engineering, Technical University of Denmark, Lyngby, Denmark (2004).

52. C. Berggreen, B.C. Simonsen, J. Sandwich Struct. Mater. 11 (7), 483 (2005)

53. C. Berggreen, B.C. Simonsen, K.K. Borum, J. Compos. Mater. 41 (4), 493 (2007).

54. B. Hayman, C. Berggreen, R. Pettersson, J. Sandwich Struct. Mater. $\mathbf{9}$ (4), 377 (2007)

55. C. Berggreen, C. Jensen, B. Hayman, in Proceedings of MARSTRUCT 2007. The 1st International Conference on Marine Structures, Glasgow, United Kingdom, 12-14 March 2007 (Taylor \& Francis 2007) pp. 413-420.

56. B. Budiansky, Comput. Struct. 16 (1), 3 (1983).

57. C. Soutis, P.T. Curtis, N.A. Fleck, Proc. R. Soc. London A 440, 241 (1993). 58. K. Vedeld, MSc degree thesis, Department of Mathematics, University of Oslo, Oslo, Norway (2007).

59. B. Hayman, J. Sandwich Struct. Mater. 9 (6), 571 (2007).

60. Federal Aviation Authority (FAA). Federal Aviation Regulations Part 23 Airworthiness standards: Normal, utility, acrobatic and commuter category airplanes. Sections 23.571, 23.572, and 23.573.

61. B. Hayman, in Theory and Applications of Sandwich Structures, R.A.

Shenoi, A.S. Groves, Y.D.S. Rajapakse, Eds. (University of Southampton, Southampton, UK, 2005) p. 351.

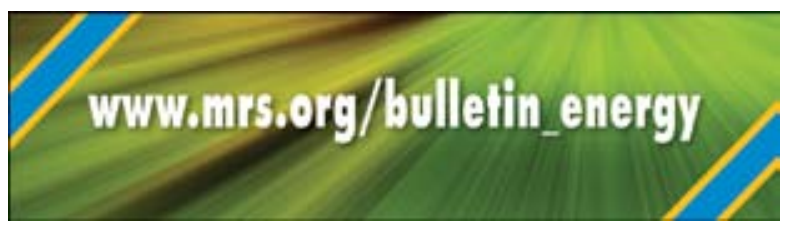

\section{ZEM-3 Measures Seebeck} Coefficient and Electrical Resistivity

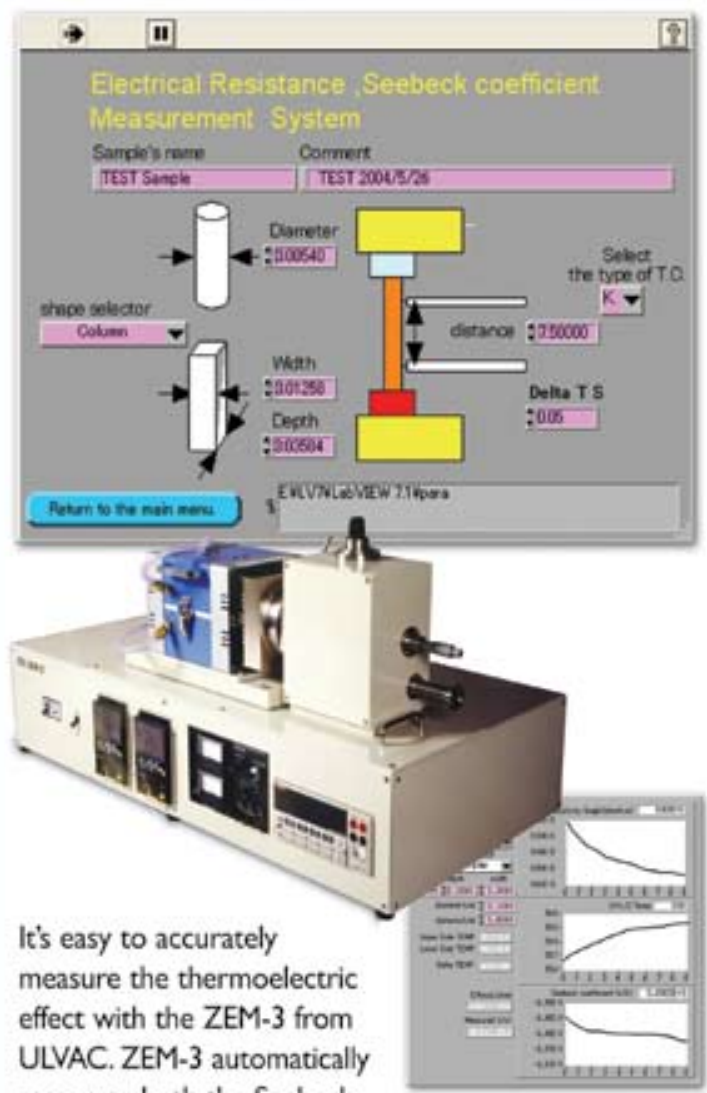
measures both the Seebeck

Coefficient and Electrical Resistivity of bulk samples, thin sheet or deposited thin film thermoelectric materials.

The bench top, computer-controlled ZEM-3 features:

- Fully automatic operation

- Operating range from -80 to $1,000^{\circ} \mathrm{C}$

- Easy sample loading and data analysis

Just enter your sample geometry, experimental parameters and data reporting preferences and the ZEM-3 does the rest. For the best in accurate and repeatable measurement, choose the ZEM-3.

With ZEM-3 -

$$
\text { Just run the samples! }
$$

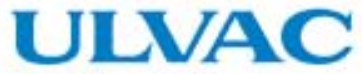

ULVAC Technologies, Inc

Methuen, MA 01844

Phone: 978-686-7550

www.ulvacicom

sales@ulvac.com 


\section{Power Tool for Grownups MultiBeam - look - build - analyze - in real time}

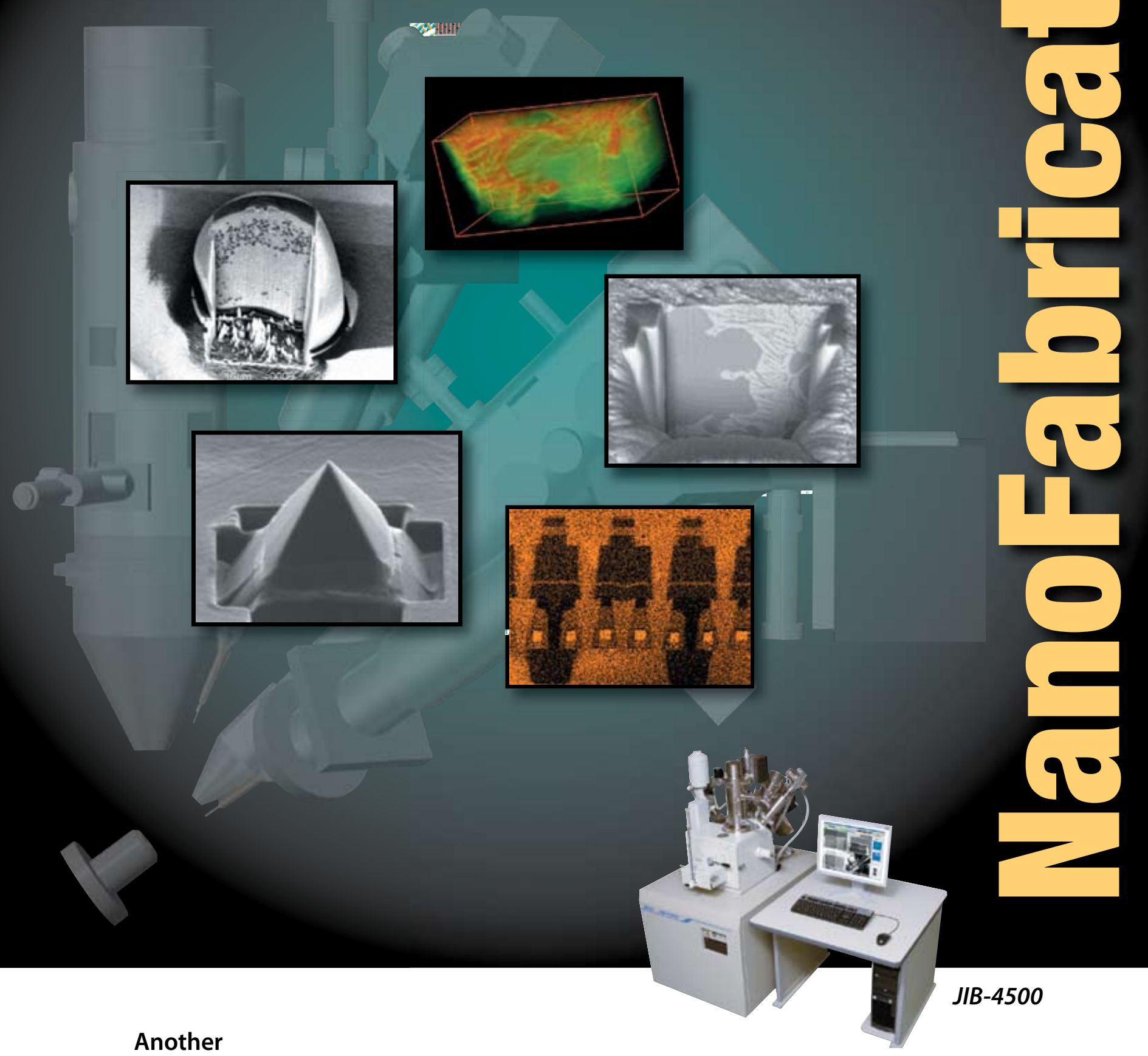

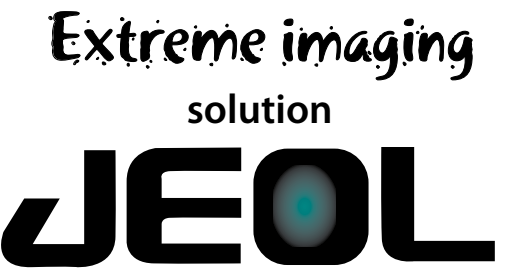

Stability $\cdot$ Productivity $\cdot$ Performance www.jeolusa.com·salesinfo@jeol.com

978-535-5900 ho says you can't afford to have it all? High-resolution imaging, bitmap milling, TEM sample prep, and high-speed slicing and sampling in real time with this all-in-one SEM/FIB. The new JEOL MultiBeam combines the world's most popular low vacuum $\mathrm{LaB}_{6}$ electron column with high resolution ion beam optics. Utilize the full power of the MultiBeam power tool for your next nanofabrication project. For more information visit www.jeolusa.com/multibeam. 